\title{
Magnetic Resonance Imaging Assessment of Bone Regeneration in Osseous Defects Filled with Different Biomaterials An experimental in vivo study
}

\author{
TUDOR SORIN POP', ALINA DIA TRAMBITAS MIRON2*, ANCA MARIA POP³, KLARA BRINZANIUC ${ }^{4}$, CRISTIAN TRAMBITAS ${ }^{14}$ \\ ${ }^{1}$ University of Medicine, Pharmacy, Sciences and Techonology of Targu Mures, Department of Orthopaedics and Traumatology, \\ 38 Gheorghe Marinescu Str., 540139, Targu Mures, Romania \\ ${ }^{2}$ University of Medicine, Pharmacy, Sciences and Techonology of Targu Mures, Department of Medical Informatics and Biostatistics, \\ 38 Gheorghe Marinescu Str., 540139, Targu Mures, Romania \\ ${ }^{3}$ University of Medicine, Pharmacy, Sciences and Techonology of Targu Mures, Faculty of Medicine, 38 Gheorghe Marinescu Str., \\ 540139, Targu Mures, Romania \\ ${ }^{4}$ University of Medicine, Pharmacy, Sciences and Techonology of Targu Mures, Department of Anatomy and Embryology, \\ 38 Gheorghe Marinescu Str., 540139, Targu Mures, Romania
}

\begin{abstract}
Noninvasive techniques, such as Magnetic Resonance Imaging (MRI) are becoming more used in the study of bone regeneration outcomes, in both animal models and human patients. Many studies have shown the potential of tissue engineering therapies to promote healing of skeletal injuries, but further research is needed to optimize these treatment options. This investigation is a continuation of other previous published studies, in which critical-sized bone defects created in the parietal bones of Wistar rats were filled with either bioglass or a biologic collagen scaffold seeded both with adipose-derived mesenchymal stem cells. The present study aims to present the applications of MRI in the assessment of the bone regeneration process in these previously created defects, at specific time intervals. MRI techniques are based on the differences between the spin-latice $T 1$ and spin-spin $T 2$ relaxation times of examined specimens or areas, compared to normal tissues. We measured the relaxation times specific to calvarial specimens with a Brukner Minispec. The results showed that the most favorable results were observed when a collagen scaffold seeded with stem cells was used. MRI enabled the detection of hard and even soft tissue changes, these findings suggesting that MRI could be an effective imaging modality for assessing changes in bone morphology and pathobiology. Furthermore, it can be used as an alternative to Computed Tomography in examining the role of various biomaterials used in bone healing, especially when ionizing radiation is contraindicated.
\end{abstract}

Keywords: MRI, animal model, bone regeneration, stem cells, collagen scaffolds

The treatment of severe bone damage is based on surgical reconstruction techniques involving the use of bone grafts; the latter come with certain disadvantages such as morbidity at the donor site, immune reactions and infections [ 1,2$]$. In order to overcome these, researchers focused on the development of tissue engineering techniques, which mean the use of a combination of cells, a biocompatible scaffold and signaling molecules that will promote the development of new bone. Data from in vitro studies regarding tissue engineering offer useful information, but the experimental conditions cannot be replicated in in vivo environment. Therefore, animal models were used to assess the biological activation of osteogenesis, osteoconduction, osteoinduction and biophysical effects that take place during bone regeneration $[3,4]$.

The rat calvarial defect was used as a model for intramembranous formation of bone, which may be less suitable for the study of biomaterials or therapies for enchondral bone development. Nevertheless, it can be successfully used to study different biomaterials, evaluate bone regeneration and tissue engineering before their possible translation to human applications [5] By definition, a critical size defect is the smallest lesion unable to heal completely without intervention over the natural lifetime of an animal. Current use of term, which according to some researchers should be abandoned, comes from these criteria, but in many experimental studies the evaluation is

*email: miron_alina_dia@yahoo.fr; Phone: +40740139905 made at a pre-established endpoint, rather than the end of natural life of a subject. Therefore, the term non-healing defect was considered to be more appropriate $[6,7]$.

Imaging techniques such as computed tomography (CT) and magnetic resonance imaging (MRI) are nondestructive, allowing serial observations at discrete timeintervals on the animal model; CT provides 3D structural images with high spatial resolution and penetration depth and is clinically translatable for late stages of regeneration. It permits a thorough evaluation of the integration and connectivity of the regenerative scaffold and stem cells with the host bone tissue $[8,9]$. However, the sensitivity of $\mathrm{CT}$ is limited in case of pre-mature/immature bone or bone like tissues and the radiation has been found to inhibit the growth of new bone and to induce bone breakdown. By contrast, MRI provides high spatial resolution and it detects modifications in tissue water content, revealing alterations of structure and/or functions of the examined tissues [10, 11].

The aim of our study was to investigate the possibility of monitoring implanted bone constructs in rat calvarial defects, their cell dynamics and regenerative reactions, by using the MRI technique. We designed an experimental study in which the healing process of critical-sized calvarial bone defects, filled with either a biologic collagen scaffold or bioactive glass, both seeded with adipose-derived messenchymal stem cells were examined. The bone regeneration characteristics were assessed by MRI and correlated to a specific time interval. 


\section{Experimental part}

Materials and methods

In this study, we performed MRI examination of rat calvarial defects filled with bioactive glass and a collagen scaffold, seeded respectively with adipose derived stem cells, obtained after two previously conducted in vivo experimental studies. This examination was approved by the Ethics Committee of our university, based on decision Nr. 137/10.11.2016. The bone defects were created according to a protocol extensively described in our previous publications. It was based on the following steps: in each animal two bone defects located in the parietal bones were made, the ones located on the right side being the study lesion, filled with either bioactive glass or a collagen scaffold and seeded both with stem cells; the defects from the left side were used as negative controls. In this way we could obtain a sufficient number of defects by using a relatively small number of animals.

The MRI techniques used in this study are based on the differences between the spin-latice T1 and spin-spin T2 relaxation times of examined specimens or areas, compared to normal tissues. The signal-to-noise ratio and the image resolution of MRI experiments are determined by the T1 and T2 relaxation times. This technique can be used to measure atomic nuclei with a cuantic number of nuclear spin $I \neq 0$, mentioning that the interpretation of experimental results are very difficult for nuclei with $\mid>1$. In our study we analyzed hydrogen nuclei $\left({ }^{1} \mathrm{H}\right)$ with $\mathrm{I}=1 / 2$.

For the measurements of relaxation times we used a BRUKER MINISPEC mq20 spectrometer using a glass tube with a diameter of $10 \mathrm{~mm}$, in which we placed the bone specimens containing the calvarial defects (fig. 1). No additional technical steps, which might have negative effects on integrity of bone calus and the correct subsequent morphologic analysis, were needed. A Larmor frequence of $19.7 \mathrm{MHz}$ at a constant temperature of $35^{\circ} \mathrm{C}$ was used and the measurement of spin-spin relaxation times was made using an impuls of $12.5 \mu \mathrm{s}$ and 7000 echoes and a magnetization time of $5 \mathrm{~s}$. The time of echoes appearance was $0,4 \mathrm{~ms}$.
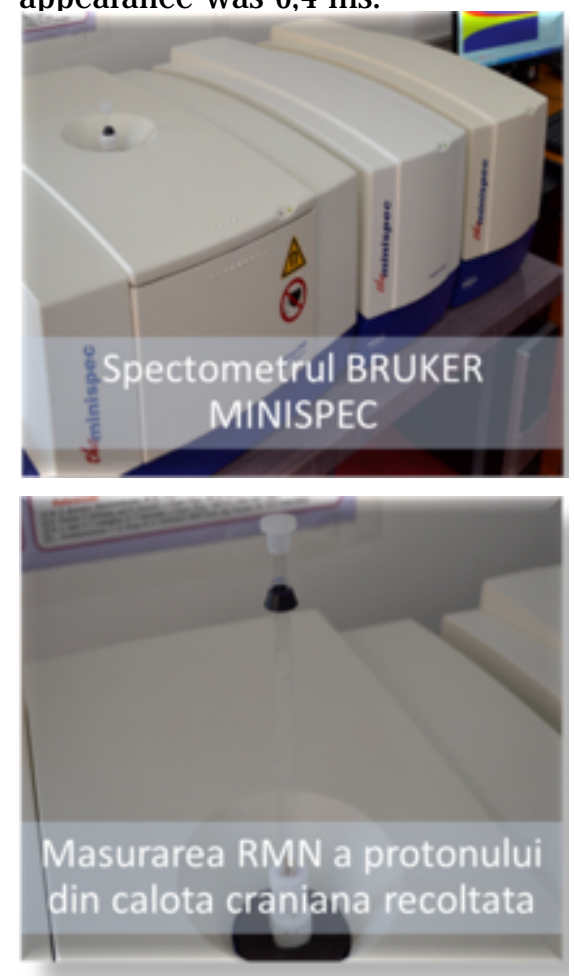

Fig. 1. MRI measurements were done using the Brucker Minispec spectrometer

We used Carr-Purcell- Meiboom-Gill (CPMG) pulse sequences with a maximum of 128 echoes in order to measure the amplitude of the signal in the indirect dimension. In this way we obtained the $T_{2}$ relaxation times and the CPMG curves were analyzed using the inverse Laplace transform of the measured data. In order to determine the distribution of spin-spin T2 relaxation times corresponding to CPMG curves we applied UPIN algorithm, obtaining the inverse Laplace transform for the analyzed data.

\section{Results and discussions}

The shapes of CPMG curves in figure $2 a$, figure $3 a$, figure $4 \mathrm{a}$ allow us to differentiate soft tissues from hard tissues in the analyzed sample. The longer the falling CPMG times (blue line in fig. 2a) the more soft tissue we have and the faster the CPMG descends the more hard tissue (red curve in fig. 2a). Exclusively analyzing these data, we cannot draw relevant conclusions regarding to ${ }^{1} \mathrm{H}$ reservoirs or the protons from different mediums with different spinspin relaxation times. In order to accomplish this we need to use the Laplace transform of CPMG descending curves (fig. 2.b, fig. 3.b and fig. 4.b).
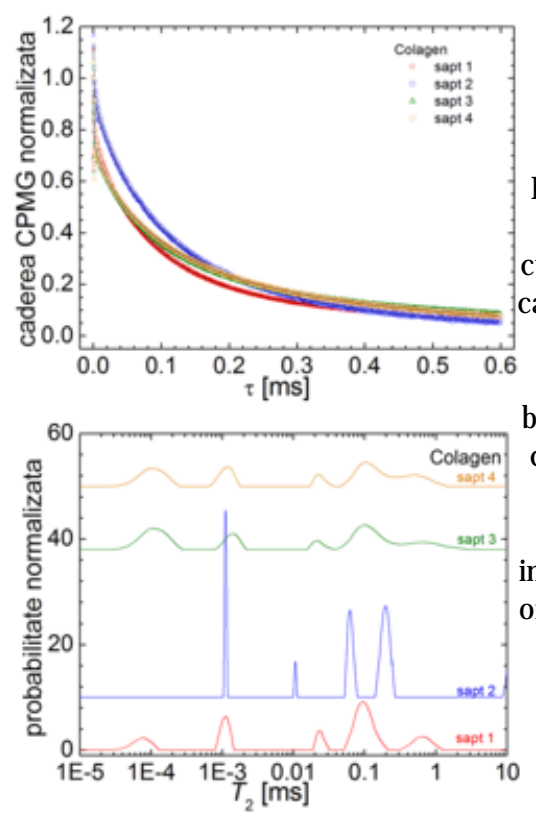

Fig. 2.a) Descending of normalized $\mathrm{CPMG}^{1}$ curves measured for the calvarial defects at 1, 2, 3 and 4 weeks after the defect was filled with bioactive glass and stem cells; b) Distribution of relaxation spin spin times T2, obtained by invers Laplace transform of these previous curves
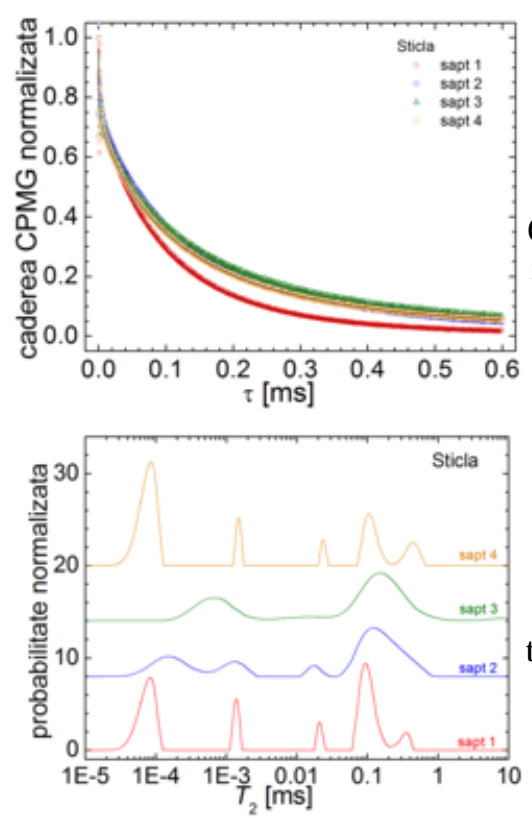

Fig. 3a) Normalized CPMG curves measured for the calvarial defects at 1, 2, 3 and 4 weeks after the bone defect was filled with a collagen scaffold and stem cells b) Distribution of relaxation spin-spin times T2, obtained by invers Laplace transform for the curves from figure $3 a$. 

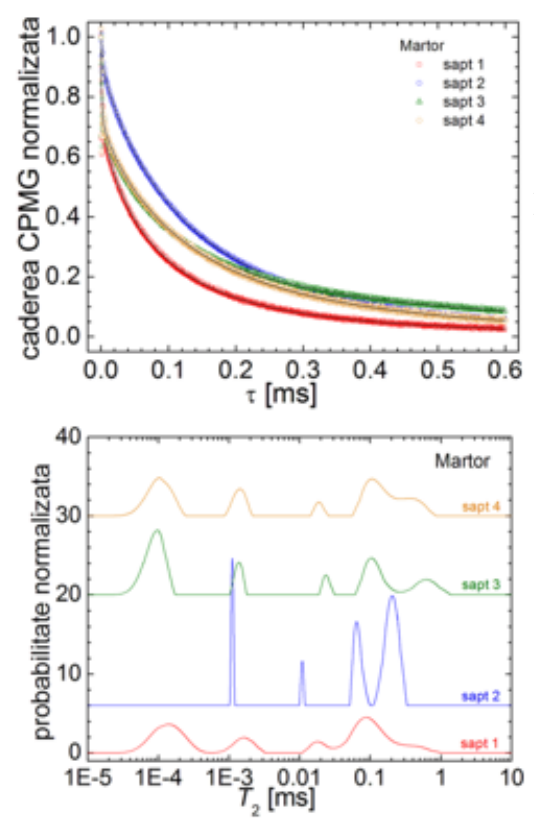

Fig. 4a) Normalized CPMG curves measured for the calvarial defects at $1,2,3$ and 4 weeks after the bone defect was created and left unfilled (control)

b) Distribution of relaxation spin-spin times T2, obtained by invers Laplace transform for the curves from (fig. 4a)

This evaluation of experimental tissues shows that in the group where we used a collagen scaffold seeded with stem cells the evolution was more favorable compared to the other group. By examining the area of interestwe noted that in the first week the hydration level was approximately equal in the collagen and bioactive glass groups but in the control one there was a dehydration due to the absence of hydrophilic structures in the defect area (fig. 5). In the $2^{\text {nd }}$ and 3 rd weeks the three groups suffer water depletion suggesting tissue reorganization. In the $3^{\text {rd }}$ and $4^{\text {th }}$ weeks there is a rehydration of the defect which certifies the formation of granulation tissue with blood vessels and extensive cell populations which contain different quantities of water.

The ideal animal model for bone tissue engineering and development of osteoinductive biomaterials should have the following major characteristics: to be highly reproducible, to be relevant for clinical situations, to allow manytypes of analysis, to permitthe assessment of various materials and to have little morbidity or mortality among animal study group. Among the numerous species used in animal experimental studies, much research has focused on rodent models; the rat calvarial defect was first described in 1973 and established only after 10 years by the work of Takagi and Urist [12]. It is reproducible, can be generated in a short time and does not need additional fixation or stabilization to skeleton.

In order to achieve ideal results in osseous defects regeneration, tissue engineering techniques need to use optimal combinations of a selected cell population, which is to be differentiated and cultured in a specific and appropriate environment. This is then transferred to a biomaterial scaffold, which will act as a template for anchoring both homing and seeded cells in order to support tissue differentiation. A biomaterial was defined by Williams as a material intended to interface with biological systems to evaluate, treat, augment or replace any tissue, organ or function of the body. [13-15]. Cooper et al [16] considered that advanced imaging technology enables the quantification of small differences in the quality and amount of bone formation in animal models, but it is imperative to develop future studies with better designs that could accurately reflect the clinical situations.

The bone content of ${ }^{1} \mathrm{H}$ protons (water, proteins, type I collagen, calcium phosphate, interosteonic lipids) can be analyzed and differentiated according to their source, using MRI longitudinal and transversal relaxation times. [17] Horch et al [18] showed that each of these bone components could include one or more distinct proton micro-medium, each characterized according to the local chemical, magnetic and electric environment. The authors showed that the collagen hosts both absorbed water and protons from bone covalent binds; on the other hand, mineral areas are rich in water with different grades of motion while the fatty acids are located in the interosteonic spaces.

The screening of bone reconstruction in calvarial defects using MRI proved to be an alternative to other methods, such as CT, due to its high resolution and noninvasive special imaging technology. Furthermore, itallows the evaluation of the osteogenic growth of an implanted tissue $[19,20]$. A well-established technique for the assessment of bone healing is micro-CT but due to the ionizing radiation emitted during this investigation, it becomes dangerous if a research subject or animal must be submitted to repeated examinations [21-23]. By contrast, MRI is based on non-ionizing radiation and highlights the soft tissues, bone marrow, periosteum and

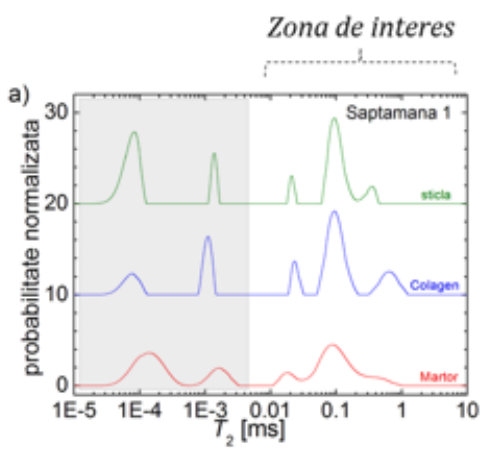

Zona de interes

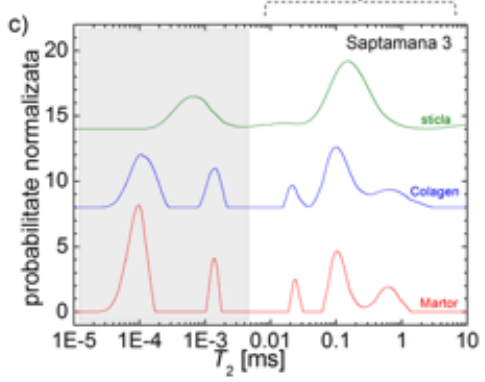

Zona de interes

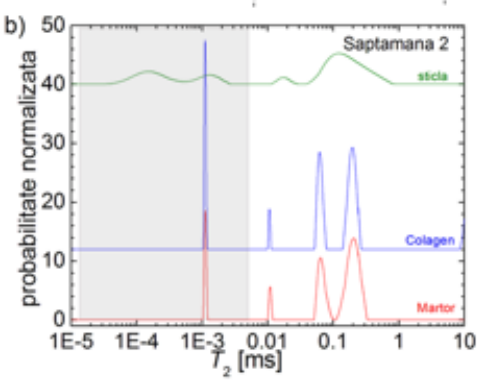

Zona de interes

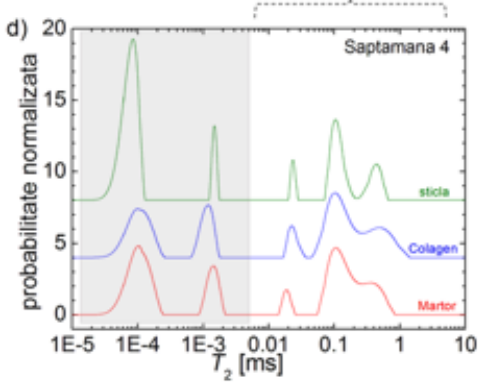

Fig. 5. Distribution of spin-spin T2 relaxation times measured for calvarial bone defects at a) 1 week; b) 2 weeks; c) 3 weeks and d) 4 weeks; left unfilled in order to be used as controls (red line), filled with collagen and stem cells (blue) filled with bioactive glass and stem cells (green) 
surrounding muscles. This technique is challenging for evaluation of small animal models, due to the high resolution needed and the artifacts that might be generated by the bone-soft tissue interfaces. However, the increased availability of the MRI range of sequences makes it possible to overcome this issue [24- 28].

Our study proved that MRI techniques can be successfully used to examine the calvarial bones in experimental animal models and to determine their chemical structure. In contrast to histologic examination which offers information of a small area, the measurements of MRI relaxation times evaluate the whole calvarial bone. Using the $T_{2}$ distribution times, we could identify the morphologic characteristics of the healing process at specific intervals (1-4 weeks). Small animal models became more interesting in the field of tissue engineering, especially for the development of biomaterials for bone regeneration. Most of the experimental studies use micro-CT imaging for longitudinal follow up, but MRI seems to be a good surrogate, due to its non-invasive properties, high contrast between tissues, multi-parametric features in one exam and the translational potential combined with the development of musculo-skeletal MRI in the clinic.

\section{Conclusions}

MRI has a tremendous potential for bone tissue engineering applications and the follow-up of the newly bone tissue regenerating within a defect. It can be used as an alternative to micro-CT and histology/ immunohistochemistry for preclinical bone tissue engineering studies, and is of great interest to noninvasively follow-up of bone repair and vascularization in humans. Furthermore, a major advantage of MRI examination is represented by the preservation of the specimens, allowing the further histologic examination.

\section{References}

1.BAROLI, B. J. Pharm Sci. 98, no. 4, 2009, p. 1317

2.GOMES, P.S., FERNANDES, M.H. Lab Anim. 45, no.1, 2011, p. 14

3.XU, H., OTHMAN, S.F., MAGIN, R.L. J of Bioscience and Bioengineering. 106, no.6, 2008, p. 515

4.MARIAPAN, Y.K., GLASER, K.J., EHMAN, R.L. Clinical Anatomy. 23, no.5, 2010, p. 497

5.PEARCE, A.I., RICHARDS, R.G., MILZ, S., SCHNEIDER, E., PEARCE, S.G. Eur Cells Mater. 13, 2007, p. 1

6.MUSCHLER, G.F., RAUT, V.P., PATTERSON,T.E., WENKE, J.C., HOLLINGER, J.O. Tissue Eng Part B Rev. 16, 2010, p.123

7.WOLFF, J., SANDOR, G.K., MIETTINEN, A., TOUVINEN, V.J ., MANNERSTROM, B., PATRIKOSKI, M., MIETTINEN, S. Ann Maxillofac Surg. 3,no.2, 2013, p. 114
8.STOICA, A.M., STETIU, A.A., BURUIAN, M., STETIU, M., MONEA, M., J. Optoelectron. Adv. M. 18, no.5-6, 2016, p.560

9.TRAMBITAS, C., POP, T.S., TRAMBITAS MIRON, A.D., DOROBANTU, D.C., BRINZANIUC K., Rev. Chim.(Bucharest), 68, no.2, 2017, p. 387 10.VISVADER, J.E., CLEVERS, H. Cell Biol. 18, no. 4, 2016, p. 349

11.TIRKKONEN, L., HAIMI, S., HUTTUNEN, S., WOLFF, J., PIRHONEN, E., SANDOR, G.K., MIETTINEN, S. Eur Cell Mater. 30, no. 25, 2013, p. 114

12.TAKAGI, K., URIST, M.R. Am Surg. 196, 1982, p. 100

13.TAUB, P.J ., YOU, J ., SPANGLER, M., MASON, J.M., LUCAS, P.A. Plast Reconstruct Surg. 123, no. 4, 2009, p. 1178

14.SZPALKI, C., SAGEBIN, F., BARBARO, M., WARREN, S.M. J Biomed Mater Res B Appl Biomater. 101, no. 4, 2012, p. 663

15.WILLIAMS, D.F. The Williams dictionary of biomaterials. Liverpool University Press. 1999

16.COOPER, G.M., MOONEY, M.P., GOSAIN, A.K., CAMPBELL, P.G., LOSEE, J.E., HUARD, J. Plast Reconstruct Surg. 125, no. 6, 2010, p. 1685

17.FANEA, L., SFRANGERU, S.A. Romanian Reports on Physics. 63, no. 2, 2011, p. 456

18.HORCH, A.R., NYMAN, J.S., GOCHBERG, D.F., DORTCH, R.D., DOES, M.D. Magnetic Resonance in Medicine. 64, 2010, p. 680

19.J ONES, A.C., ARNS, C.H., SHEPPARD, A.P., HUTMACHER, D.W., MILTHORPE, B.K., KNACKSTEDT, M.A. Biomaterials. 28, 2007, p. 2491 20.ARVIDSON, K., ABDALLAH, B.M., APPLEGATE, L.A. et al. J Cell Mol Med. 15, 2010, p. 718

21.TAHA, M.A., MANSKE, S.L., KRISTENSEN, E., TAIANI, J.T., KRAWETZ, R., WU, Y. et al. J of Magnetic Resonance Imaging. 38, 2012, p. 231

22.de GRAAF, R.A., BROWN, P.B., MCINTYRE, S., NIXON, T.W., BEHAR, K.L., ROTHMAN, D.L. Magnetic Resonance in Medicine. 56, 2006, p. 386

23.MILES, J.D., WEINHOLD, P., BRIMMO, O., DAHNERS, L. J Orthop Res. 29, 2010, p. 109

24.LIANG, H. W.K., SHIMER, A.L., Li, X., BALIAN, G., SHEN, F.H. Bone. 47, 2010, p. 197

25.CHEN, J., WANG, Q., ZHANG, H., YANG, J., WANG, J., BERKOWITZ, B.A., WICKLINE, S.A., SONG, S.K. Magnetic Resonance in Medicine. 59, 2008, p. 731

26.NAIR, G., SHEN, Q., DUONG, T.Q. Neuroimaging. 20, 2010, p. 126 27.FILHO, B., MIRON, ALINA DIA, SATOH, I., GENSEL, J., MARTIN, H.: Modeling and Measuring Quality of Context Information in Pervasive Environments. AINA2010: 690-697

28. POP, T.S., POP, A., M., TRAMBITAS MIRON, A., D., BRINZANIUC, K., GURZU, S., TRAMBITAS, C., In vivo Evaluation of a Collagen Scaffold Preconditioned with Adipose-derived Mesenchymal Stem Cells Used for Bone Regeneration A histological study, Mat. Plast., 55, no. 4, 2018, p. 691

Manuscript received: 21.12.2018 